\title{
U BASICの化学計算への応用
}

\author{
成沢 芳男*、宮前 雄一 \\ 立教大学理学部化学科 $\bar{\top} 171$ 東京都豊島区西池袋3-34-1
}

(Recieved at Febrary 8, 1993; Accepted at April 30, 1993)

U B A S I Cにより水の密度テータ及びこれを変形して䙓にしたデータを用い、維形 の最小 2 乗近似計算を行い、B A S I C及びF O R T R A Nの結果と比较検討した。その 結果、N88B A S I Cでは 12 次元までしか計算できず、またM S - F O R T R A Nでは 50 次元まで計算できたが、精度的に問題があった。この点はS u n F F R T R A Nで 4 倍精度の計算によって検討した。

Keywords: Application of UBASIC, Least squares method, Curve fitting, FORTRAN

I. 緒言 U B A S I C の化学計算への応用について述へる。U B A S I C は木田祐司” によって開発された、巨大整数計算のための多倍長計算用 B A S I Cで、2600 析の整 数計算および実数計算、更には 1300 析の愎素数計算と有理数計算ができる。その他に 整数論のための関数や䙓素数をサポートした初等関数も扱えるので、数学の分野では種々 応用されているか、残念ながら化学分野への応用はこれまでない。

化学計算においては現在最も広く利用されている言語はF ORTRANであり、それに 代わる言語はまだ開発されていない。われわれはU B A S I CをF.ORTRANに代わる ものとして提案しようという考えではなく、個别の計算で非常に高精度を必要とする場合 に、U B A S I C が大変に威力を発揮することをいくつかの計算甽によって示そうと思う。

U B A S I C はパソコンで 2500 析の $\pi$ の計算をわすか 6 秒で実行する。これはこれ までの言語では達成できない能力で、今後その高精度演算機能は化学の色々な分野で応用 されるであろう。 能テストで日米欧の技術競争があって、数万浙の計算を正確に行うことが報告されている。 しかしスーパーコンピューターは誰でも気軽に使えるものではなく、また ことが目的ではない。化学計算でよく亚遇する問題は最小 2 乗近似であろう。例えば多項 式近似により最小 2 乗を行なおうとすると多項式のベキに相当する次数のマトリックス計 算をする必要が生じる。近似の次数を上げれば一般に精度は良くなると考えられるか、比 大な計算のため計算唄差が大きくなり、逆に精度は下がる。しかしこれまでそのような計 算謓差を検証する高精度演算ソフトがなく、化学の分野で系統的な検討が行われてこなか った。本論文では最小 2 乗近似の計算俱差を検討するためにBASIC、F ORTRAN 及びU B A S I Cのプログラムを作成し、演算俱差について論じる。 
II. 序論 著者はすでに水の密度の多項式近似と測容器の補正 ${ }^{2)}$ の論文で、B A S I Cに

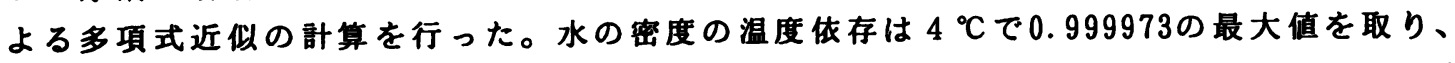
$0{ }^{\circ} \mathrm{C}$ から $30.5{ }^{\circ} \mathrm{C}$ の範囲で0.999841 0.995494の変化しかなく、比較的次数の小さい多 項式で近似でき、なおかつ有効桁数も小数点以下 7 析程度であるため当時の 8 ビットパソ コンで速度、精度とも充分であった。しかし更に複雑な曲線を最小 2 乗近似するためには、 速度、精度とも高度なすのが要求され、一举に 32 ビットパソコンによる高精度計算が必 要となるが、高次元マトリックス計算においてどれだの演算俱差が生じるのかと言う点 に関しては全く研究例がない。そこでUＢＡＳＩＣを用い、他言語による計算結果と比較 し、その有用性について論じたい。

\section{III. 理論}

1.最小 2 乗法 ${ }^{8)}$. 4)

最小 2 乗近似は区間（ $\mathrm{a} ， \mathrm{~b} ）$ で与えられた関数 $\mathrm{g}(\mathrm{x})$ に対して、通当な条件を满足 する関数の中から、2 乗俱差

$$
E=\int_{0}^{b}[g(x)-f(x)]^{2} d x
$$

を最小にするf（x）を選定する方法である。

区間 $(\mathrm{a}, \mathrm{b})$ で定美された関数 $\mathrm{g}(\mathrm{x})$ がその区間内に指定された選点 $\left\{\mathrm{x}_{i}\right\} \quad i=1^{n}$ と、 その上の值 $\left\{\mathrm{g}\left(\mathrm{x}_{\mathrm{i}}\right)\right\}: \mathrm{I}^{\mathrm{n}}$ とのみによって与えられている場合、適当な条件を满足する

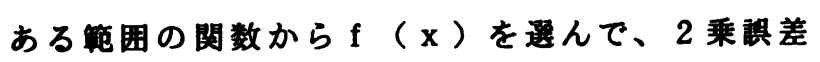

$$
E=\sum_{i=1}^{n}\left[g\left(x_{i}\right)-f\left(x_{1}\right)\right]^{2}
$$

を最小にすればよい。

$\mathrm{f}(\mathrm{x})$ がある既知関数系 | $\mathrm{f} k$ ( $\mathrm{x})\}$ の 1 次結合として

$$
f(x)=\sum_{k=1}^{m} a_{k} f_{k}(x) \quad(m \leqq n)
$$

で与えられる場合には、2 乗俱差 $\mathrm{E}$ を最小にする条件方程式は

$$
\left.\begin{array}{l}
\sum_{i=1}^{m} A_{k i} a_{i}=B_{k} \quad(k=1,2, \cdots, m) \\
\sum_{i=1}^{n} f_{k}\left(x_{i}\right) f_{1}\left(x_{i}\right)=A_{k}, \quad \sum_{i=1}^{n} g\left(x_{i}\right) f_{k}\left(x_{i}\right)=B_{k}
\end{array}\right\}
$$

であろ。

\section{G a U S S の消去法 ${ }^{3) .8) 。 1) ~}$}

一証に n元連立 1 次方程式

$$
\begin{array}{r}
a_{11} x_{1}+a_{12} x_{2}+\cdots \cdot+a_{1 n} x_{n}=b_{1} \\
a_{21} x_{1}+a_{22} x_{2}+\cdots \cdot \cdot+a_{2 n} x_{n}=b_{2} \\
\cdot \cdot \cdot \cdots \cdot \cdot \cdot \cdot \cdot \\
a_{n 1} x_{1}+a_{n 2} x_{2}+\cdots \cdot \cdot+a_{n n} x_{n}=b_{n}
\end{array}
$$

を解くには、(2-1)の両辺を $\mathrm{a}_{11}$ で割る。

$1 \mathrm{x}_{1}+\mathrm{a}_{12} \mathrm{x}_{2}+\cdots \cdot+\mathrm{a}_{1 \mathrm{n}^{\prime}} \mathrm{x}_{\mathrm{n}}=\mathrm{b}_{1}{ }^{\prime}$ 
ただし $a_{12}{ }^{\prime}=a_{12} / a_{11}, a_{1 n^{\prime}}=a_{1 n} / a_{11}, b_{1}^{\prime}=b_{1} / a_{11}$

である。これに $a_{21}$ を掛けて(2-2)から引く。

$$
\begin{aligned}
& a_{21} x_{1}+a_{22} x_{2}+\cdots \cdot \cdot \cdot \cdot+a_{2 n} x_{n}=b_{2} \\
& -\frac{a_{21} x_{1}+a_{21} a_{12} x_{2}+\cdots \cdot+a_{21} a_{1 n^{\prime}} x_{n}=a_{21} b_{1}}{0 x_{1}+a_{22} x_{2}+\cdots \cdot \cdot \cdot \cdot+a_{2 n^{\prime}} x_{n}=b_{2}}
\end{aligned}
$$

ただし $a_{22}{ }^{\prime}=a_{22}-a_{21} a_{12}{ }^{\prime}, ・ ・ ・ ・ a_{2 n}^{\prime}=a_{2 n}-a_{21} a_{1 n^{\prime}}$,

$$
\begin{aligned}
& b_{2}^{\prime}=b_{2}-a_{21} b_{1}^{\prime} \text { である。以下同様にして } \\
& 0 x_{1}+a_{n 2}^{\prime} x_{2}+\cdots ・ ・++a_{n n}^{\prime} x_{n}=b_{n}^{\prime}
\end{aligned}
$$

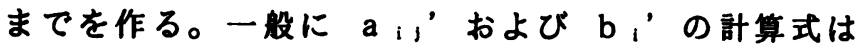

$$
a_{i j}=a_{i j}-a_{i 1} a_{1 j}, b_{i}^{\prime}=b_{i}-a_{i 1} b_{1}
$$

である。

これでx ${ }_{1}$ が消去された。

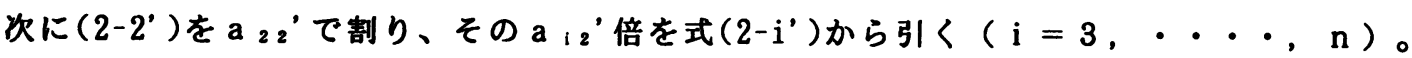
その祭の係数の計算式は

$$
\begin{aligned}
& a_{21} 1^{\prime}=a_{21} 1^{\prime} / a_{22}{ }^{\prime} \quad b_{2}^{\prime}=b_{2}^{\prime} / a_{22}{ }^{\prime} \\
& a_{1 j}{ }^{\prime}=a_{1 j}-a_{12}^{\prime} a_{21}{ }^{\prime} \quad b_{1}^{\prime}{ }^{\prime}=b_{1}^{\prime}-a_{12} b_{2}{ }^{\prime}
\end{aligned}
$$

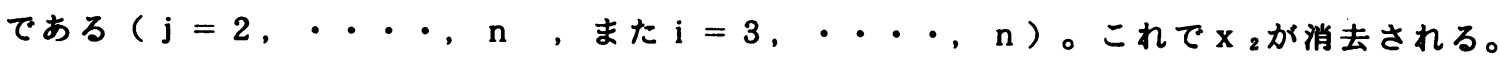
$\rightarrow$ 消去の第 2 段

あとは同様にして第 $\mathrm{k}$ 段の計算は次のようになる。

$$
\begin{aligned}
& a_{k j}(k)=a_{k j}(k-1) / a_{k k}(k-1) \quad b_{k}(k)=b_{k}(k-1) / a_{k k}(k-1) \\
& (j=k, \cdots \cdot, n) \\
& a_{i j}(k)=a_{i j}(k-1)-a_{i k}(k-1) a_{k j}(k) \\
& (\mathrm{i}=\mathrm{k}+1, \cdots \cdot \mathrm{n} \quad \text { また } \mathrm{j}=\mathrm{k}, \cdots \cdots, \mathrm{n}) \\
& b_{i}(k)=b_{1}(k-1)-a_{i k}{ }^{(k-1)} b_{k}(k) \quad(i=k+1, \cdots, n)
\end{aligned}
$$

ただし右肩の(k-1)は「第 $\mathbf{k}-1$ 段の結果」を表す。このような処理を $\mathbf{k}=\mathbf{n}-1$ まで実

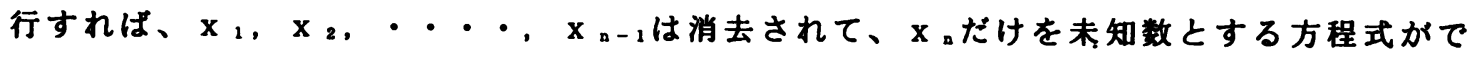
きる。

$$
x_{n}=b_{n}(n-1) / a_{n}(n-1)
$$

そして得られた結果を順に前の式に代入していけば、残りの未知数が全部求まる。

$$
\begin{array}{r}
x_{k}=b_{k}(k)-a_{k n}(k) x_{n}-a_{k, n-1}(k) x_{n-1}-\cdots \cdots-a_{k \cdot k+1}(k) x_{k+1} \\
(k=n-1, \cdot \cdots \cdot 1)
\end{array}
$$

\section{3.曲線のあてはめ8}

離散的な点で与えられたデータに滑らかな曲線をあてはめることを考える。テータは

$$
\begin{aligned}
& \text { 点 } x_{1}, x_{2}, \cdots \cdots \cdot x_{n} \\
& \text { 值 } y_{1}, y_{2}, \cdots \cdots, y_{n}
\end{aligned}
$$

とし、これから近似式 $\mathrm{y}=\mathrm{f}(\mathrm{x})$ を作ることが目的である。一般にn個のパラメータ

を含む関数 $\mathrm{f}\left(\mathrm{x}, \mathrm{p}_{1}, \mathrm{p}_{2}, \cdots \cdots, \mathrm{p}_{\mathrm{n}}\right)$ を作り

$$
f\left(x_{1}, p_{1}, p_{2}, \cdots, p_{n}\right)=y_{i}(i=1,2, \cdots, n)
$$




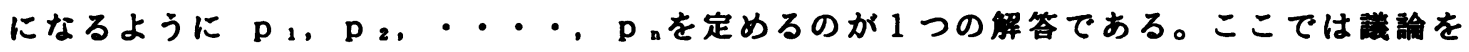
简単にするために、 $\mathrm{f}_{\text {が }} \mathrm{p}_{1}, \mathrm{p}_{2}$, ・・・・, $\mathrm{p}_{\mathrm{n}}$ に関して線形 1 次の形

$$
f(x)=p_{1} \phi_{1}(x)+p_{2} \phi_{2}(x)+\cdots \cdot \cdot+p_{n} \phi_{n}(x)
$$

で表されるとする。U B A S I C による数值計算の演算精度を諭ずるので裉雑な非線形モ デルは考虑しない。このようにすれば(3-2)は

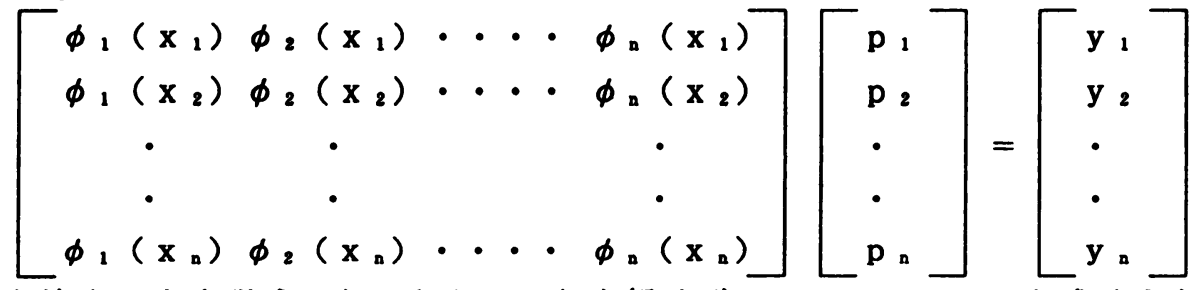

という連立 1 次方程式になるから、これを解けば $\mathrm{p}_{1}, \cdots \cdots ・ ・ \mathrm{p}_{\mathrm{n}}$ が求められる。

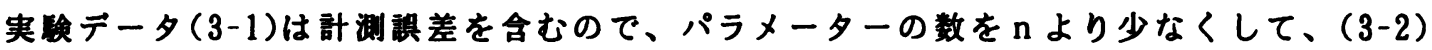
の代わりに

$$
\sum_{i=1}^{m}\left\{f\left(x_{1}, p_{1}, p_{2}, \cdots \cdots, p_{m}\right)-y_{i}\right\}^{2}
$$

が最小という条件でパラメーターを決める方が、自然な結果が得られる。式(3-5)を满たす $\mathrm{p}_{1}$, ・・・, $\mathrm{p}_{\mathrm{n}}$ を求めるには

$$
\begin{array}{r}
\frac{\partial}{\partial p_{i}}=\sum_{i=1}^{m}\left\{f\left(x_{i}, p_{1}, p_{2}, \cdots \cdot, p_{m}\right)-y_{i}\right\}^{2}=0 \\
(i=1, \cdots \cdot \cdots, m)
\end{array}
$$

を連立方程式として解けば良い。f（x) が式（3-3)の形の場合には、これは

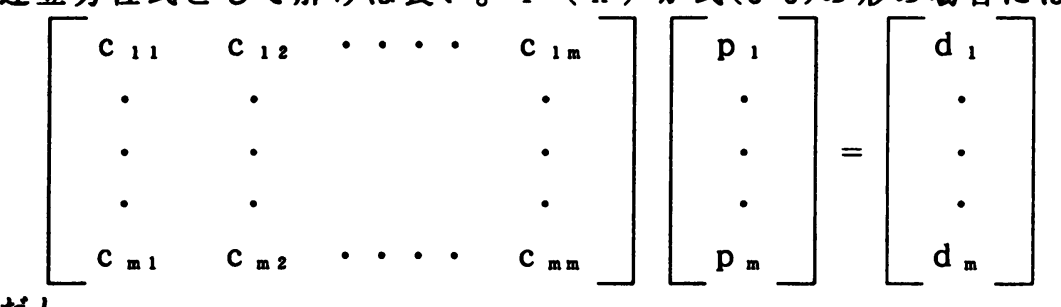

ただし

$$
\begin{aligned}
c_{i j} & =\sum_{k=1}^{m} \phi_{i}\left(x_{i}\right) \phi_{i}\left(x_{k}\right) \\
d_{i} & =\sum_{k=1}^{m} \phi_{i}\left(x_{k}\right) y_{i}
\end{aligned}
$$

となる。式(3-7)は正規方程式と呼ばれる。

IV. 計算計算に用いた B A S I C 及びF O R T R A Nのプログラムは水の密度を求め ろ多項式近似の計算に用いたもの2)を一部修正して用いた。B A S I Cは高精度演算を、 F ORTRANはMS - F ORTRANで倍精度演算、S u n - F ORTRANで 4 倍精 度演算を行った。U B A S I C B A S I Cプログラムを改良して用いた。

$0{ }^{\circ} \mathrm{C}$ から $30.5{ }^{\circ} \mathrm{C}$ まて $0.5^{\circ} \mathrm{C}$ 刻みの水の密度デタのを用いB A S I C、F O R T R A N及びU B A S I Cプログラムによる各次元ことの計算結果とテータとの差の 2 乗和を 求めた。用いたパソコンは演算コプロセッサーを内蔵したNEＣＰＣ９８０1ＲA及び P C 9801 F A であり、またF ORTRAN計算はM S - F O R T R A N V e r. 5 . 


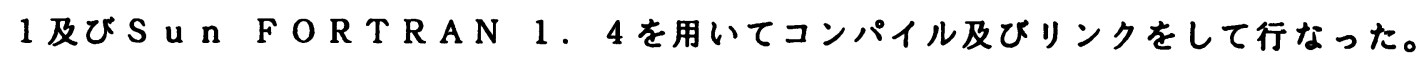

V. 結果と考察 B A S I C、F O R T R A N及びU B A S I C プログラムによる各次元 ことの計算結果と水の密度データとの差の 2 乗和を計算した。 $0{ }^{\circ} \mathrm{C}$ から $30.5{ }^{\circ} \mathrm{C}$ まの 水の密度は変化が小さく、5 次の多項式で近似すれば十分であって、水の密度データの最

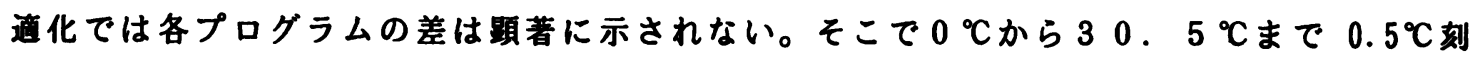
みの 62 ヶのデータを複雑な変化のおるものに变え、より高次の多項式でなけれは近似で

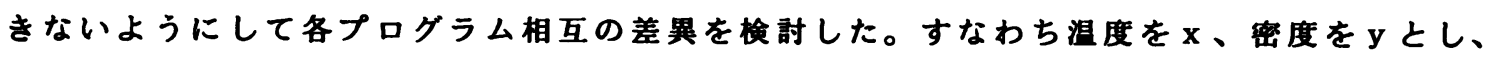
新しい縦軸の值を $\mathrm{Y}$ とる。プログラムの内容を変えずにテータだけを変更し、また計算 結果をグラフィック表示する関係から次式

$$
Y=0.80 y+\sin x \times 0.0003+0.199
$$

を計算して、水の密度のテータと同様に $\mathrm{x}$ の值が 0 から 30.5 まで 0.5 刻みで 62 ヶの テータ点を持つテータファイルを作成し、 $\mathrm{x} と \mathrm{Y}$ の関係曲線に最もよくあてはまる多項式 近似を行った。各プログラムによる水の密度テータおよび(A)式のテータについての俱差 の 2 乗和を計算し、結果を Table 1 および 2 に示す。ただし B S I Cの計算はS u n F ORTRAN及ひUBASICのものと 12 次元まで全く同じであったが、1 3 次元以 降はOVERFLONのメッセージが表示され計算不能になったので、表には示さなかった。表中 の DIMENSION (次元) はマトリックスの次元を示し、多項式の最高べキ数はこれより1だ け減したものである。表から明かな通りUＢＡＳＩＣは多倍長計算ソフトの特長を示し、 いずれのテータでも50 次元まで計算俱差が溥減した。5 1 次元以上の計算は実行してい ないが、次元数の限界はコンピューターのメモリ環境によって異なり、U B A S I Cの限 界ではない。

U B A S I Cについて (A)式のデータを10 次元及び 20 次元で近似したときの最道化 の状況をFig. 1 に示す。10 次元では曲線のあてはめはかなり不霂足であるが、20 次元 では最適化はかなり满足すべきものであった。

Table 1 のF ORTRAN及ひUＢASIＣの俱差の 2 乗和を次元に対してプロットし、 水の密度に対する結果をFig. 3 (a)に、（A）式に対する結果をFig. $3(\mathrm{~b}) に$ 示す。Fig. 3 （a）の結果が示す通り、比較的低次で多項式近似できる場合は各プログラムによる差は影 著に現れない。ただしMS - F O R T R A N 場合は 30 次元と 39 次元のところに特異 的に精度が㦞くなるところがあるが、この点に関しては後に議論する。Fig. 3(b) の結果 はMS-FORTRANもUBAS I C P U n - F ORTRANと同じく11 次元まて は全く同じであるが、1 2 次元以降は俱差が減少しないし、バラッキがひどい。これは S - F ORT R A N がDOUBLE PRECISION型の計算をするために、精度的に道さないことを 示す。なお(A)式のテータについてUBAS I C及びS u n - F O R T R A N の俱差の力 一ブは単調減少ではなく、門状になったが、デタが復雑になったため最道化するのに より高次の多項式近似が必要であることを示している。

なおFig. 3 (a)及び(b)のM S - F ORTRANの瞋差の 2 乗和が 30 次元と 39 次元で 特異的に大きくなることに関して原因は明かでないか、、理由はいくつか考えられる。即ち 1 : パソコンを用いていること、 2 : 演算コプロセッサーを使っていること、 $3: \mathrm{MS}-$ 
F O R T R A Nのコンパイラー及びリンカーを使っていること及び 4 ：プログラムが正し く曹かれていないこと。そこでEthernetを通してPC９８０１１ＦＡを富士通Ｓ４／４７０ ワークステーションにアクセスし、Allied Telesisの通信ソフトTCP/IPを用いてプログラ ムおよびテータを転送し、ワークステーション上で各次元毎の水の密度データ及ひ（A） 式に対する俱差の 2 乗和を計算した。なお央数計算はすへてQUADRUPLE PRECISION 型で行 った。Fig. 3 から明かなように、M S - F O R T R A N はDOUBLE PRECISION型で、精度上 問題があったが、ワークステーションによるQUADRUPLE PRECISION の計算ではこの点が改 䡬された。従って、M S - F O R T R A N 計算結果に異常が生じのは上記 4 項のプロ グラムが正しく書かれていないことであるという理由は除かれる。また上記 1 ○ 3 項は 1 つに䌿めることができ、パソコンによる倍精度演算では精度上問題があることを示してお り、それ以上原因を明らかにするにはＭS－FＯRＴＲＡＮの計算過程を詳細に検討する 必要がある。それは今回のU B A S I Cに関する性能検查の問題ではないので、これ以上 の鉷論はしない。

再びFig. 1 の話に戻って、Fig.1のグラフはUBAＳＩＣで計算した結果ではあるか、、 Table 2 より1次元から 23 次元の籁围においてはUBASICとS n n F O R T A $\mathrm{N}$ の計算結果は同しであるので、この 10 次元と 20 次元についての結果を表したグラフ は、もし S u.n - F O R T R A Nで計算した結果を同様にグラフ表示しても同じすのが得 られると言える。すなわち、（A）式のテータではUBAS I CとS un - F O R T R A N の間の頼著な差はグラフ上では見られない。しかしながら、（A）式のテータでは 20 次 元でほほ满足な近似が出来ているか、Sun-FORTRANとUＢＡＳＩが同じ俱差 の 2 乗和を与えているのは 23 次元までであり、より襍なテータを用いれば精度の差が 明らかになると考え、水の密度のテータを（A）式より更に䙡雑にした次式

$$
\mathrm{Y}=0.80 \mathrm{y}+\sin 2 \mathrm{x} \times 0.0003+0.199
$$

を計算して、（A）式のデータと同様に62 ケのテータ点を持つテータファイルを作成し、 MS - F ORTRAN、S un-FORTRAN、およひUUASICの 3 種類の言語で

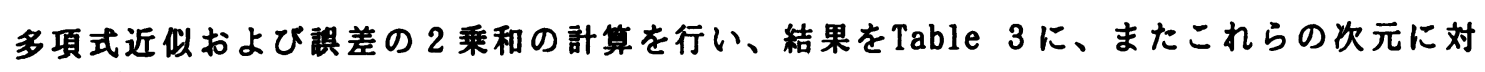
するプロットをFig. 4 に示す。Fig. 4 より明らかなように、（B）式のテータを用いた場 合には、U B A S I Cで計算した俱差の 2 乗和は 27 次元から急擞に減少しているが、S un - F O R T R A Nの結果はあたかもFig. 3(b)のMS - F ORTRANのような、俱差 の 2 乗和が娍少しないバラッキのひどい結果となった。

U B A S I Cについて (B) 式のデータを 20 次元及び 35 次元で近似したときの最道 化の状況をFig. 2 に示す。（B）式のデータでは、20 次元では满足な曲線のあてはめか できていないか、35 次元ではかなり满足な結果が得られた。Sun - F O R T R A Nで U B A S I C と同じ結果が出せる限界が 23 次元であり、Fig. 2 の 20 次元の近似曲線は ほほS u n - F O R T R A N プログラムの近似できる限界に相当するので、このグラフか らもUBASICの精度的な優秀性が確認できた。

従来、謓差の 2 乗和を計算して評洒をするための高精度計算プログラムがなかったので、 結果を比较することができなかったが、今回U B A S I C を用いて、広く使われている基 本的な言語の計算精度を論じることができた。 
Table 1 水の密度デー夕使用時の咱差の 2 乗和

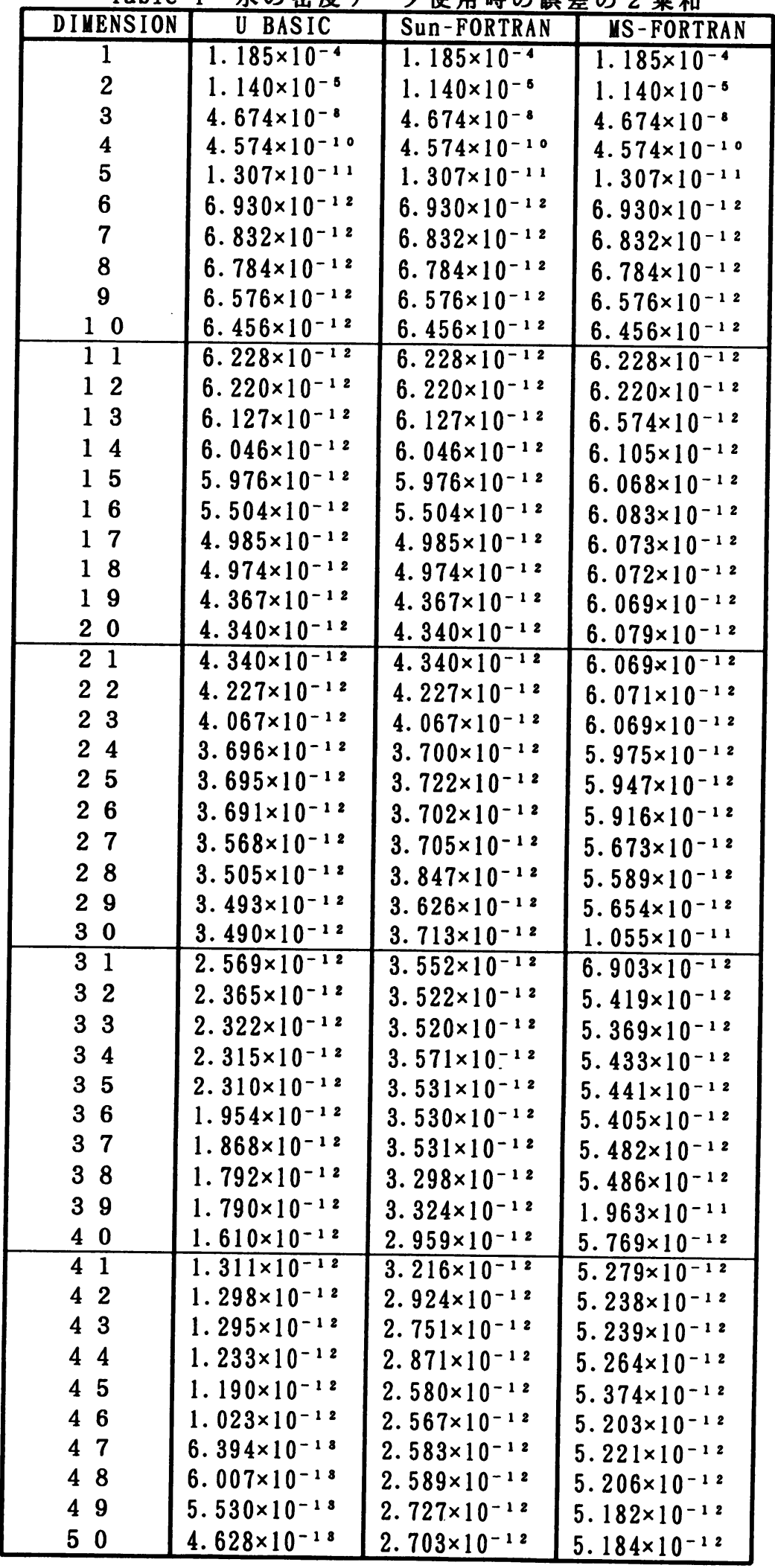


Table 2 (A) 式によるデー夕使用時の稹差の 2 乗和

\begin{tabular}{|c|c|c|c|}
\hline DIMENSION & U BASIC & Sun-FORTRAN & MS-FORTRAN \\
\hline 1 & $8.243 \times 10^{-6}$ & $8.243 \times 10^{-5}$ & $8.243 \times 10^{-5}$ \\
\hline 2 & $9.912 \times 10^{-6}$ & $9.912 \times 10^{-6}$ & $9.912 \times 10^{-6}$ \\
\hline 3 & $2.663 \times 10^{-6}$ & $2.663 \times 10^{-6}$ & $2.663 \times 10^{-6}$ \\
\hline 4 & $2.626 \times 10^{-6}$ & $2.626 \times 10^{-6}$ & $2.626 \times 10^{-6}$ \\
\hline 5 & $2.615 \times 10^{-6}$ & $2.615 \times 10^{-6}$ & $2.615 \times 10^{-6}$ \\
\hline 6 & 2. $496 \times 10^{-6}$ & 2. $496 \times 10^{-6}$ & 2. $496 \times 10^{-6}$ \\
\hline 7 & 2. $441 \times 10^{-6}$ & $2.441 \times 10^{-6}$ & $2.441 \times 10^{-6}$ \\
\hline 8 & 2. $441 \times 10^{-6}$ & 2. $441 \times 10^{-6}$ & 2. $441 \times 10^{-6}$ \\
\hline 9 & 2. $373 \times 10^{-8}$ & $2.373 \times 10^{-6}$ & 2. $373 \times 10^{-8}$ \\
\hline 10 & $1.984 \times 10^{-6}$ & $1.984 \times 10^{-6}$ & $1.984 \times 10^{-6}$ \\
\hline 11 & $1.974 \times 10^{-6}$ & $1.974 \times 10^{-6}$ & $1.97 .4 \times 10^{-6}$ \\
\hline 12 & $1.819 \times 10^{-6}$ & $1.819 \times 10^{-6}$ & $1.822 \times 10^{-6}$ \\
\hline 13 & 1. $648 \times 10^{-6}$ & $1.648 \times 10^{-6}$ & 2. $137 \times 10^{-6}$ \\
\hline 14 & $6.954 \times 10^{-7}$ & $6.954 \times 10^{-7}$ & 1. $758 \times 10^{-6}$ \\
\hline 15 & 5. $137 \times 10^{-7}$ & 5. $137 \times 10^{-7}$ & $6.168 \times 10^{-7}$ \\
\hline 16 & $1.042 \times 10^{-7}$ & $1.042 \times 10^{-7}$ & 4. $114 \times 10^{-6}$ \\
\hline 17 & $6.290 \times 10^{-8}$ & $6.290 \times 10^{-8}$ & $7.690 \times 10^{-7}$ \\
\hline 18 & $7.238 \times 10^{-9}$ & $7.238 \times 10^{-\theta}$ & 7. $103 \times 10^{-7}$ \\
\hline 19 & 3. $700 \times 10^{-8}$ & $3.700 \times 10^{-0}$ & $5.967 \times 10^{-7}$ \\
\hline 20 & $2.773 \times 10^{-10}$ & 2. $773 \times 10^{-10}$ & $1.982 \times 10^{-6}$ \\
\hline 21 & $1.207 \times 10^{-10}$ & $1.207 \times 10^{-10}$ & $4.601 \times 10^{-7}$ \\
\hline 22 & $1.385 \times 10^{-11}$ & $1.385 \times 10^{-11}$ & $2.515 \times 10^{-7}$ \\
\hline 23 & $6.539 \times 10^{-12}$ & $6.539 \times 10^{-12}$ & 3. $169 \times 10^{-1}$ \\
\hline 24 & $5.003 \times 10^{-12}$ & $5.035 \times 10^{-12}$ & $2.878 \times 10^{-7}$ \\
\hline 25 & 4. $998 \times 10^{-12}$ & 5. $188 \times 10^{-12}$ & $3.671 \times 10^{-7}$ \\
\hline 26 & $4.940 \times 10^{-12}$ & 4. $997 \times 10^{-12}$ & 3. $568 \times 10^{-7}$ \\
\hline 27 & 4. $940 \times 10^{-12}$ & $4.950 \times 10^{-12}$ & $1.801 \times 10^{-7}$ \\
\hline 28 & $4.825 \times 10^{-12}$ & $4.940 \times 10^{-12}$ & $1.211 \times 10^{-7}$ \\
\hline 29 & 4. $806 \times 10^{-12}$ & 4. $940 \times 10^{-12}$ & $1.276 \times 10^{-7}$ \\
\hline 30 & $4.795 \times 10^{-12}$ & 4. $945 \times 10^{-12}$ & $4.649 \times 10^{-6}$ \\
\hline 31 & $4.236 \times 10^{-12}$ & $4.926 \times 10^{-12}$ & $1.985 \times 10^{-7}$ \\
\hline 32 & 4. $140 \times 10^{-12}$ & $4.908 \times 10^{-12}$ & $1.602 \times 10^{-7}$ \\
\hline 33 & $4.114 \times 10^{-12}$ & 4. $918 \times 10^{-12}$ & $1.284 \times 10^{-7}$ \\
\hline 34 & $4.094 \times 10^{-12}$ & 5. $487 \times 10^{-12}$ & 7. $423 \times 10^{-7}$ \\
\hline 35 & $3.986 \times 10^{-12}$ & $4.879 \times 10^{-12}$ & $1.710 \times 10^{-7}$ \\
\hline 36 & $3.506 \times 10^{-12}$ & 4. $748 \times 10^{-12}$ & $9.418 \times 10^{-8}$ \\
\hline 37 & $3.346 \times 10^{-12}$ & 4. $745 \times 10^{-12}$ & 8. $470 \times 10^{-8}$ \\
\hline 38 & $3.235 \times 10^{-12}$ & $4.664 \times 10^{-12}$ & $2.022 \times 10^{-7}$ \\
\hline 39 & 3. $112 \times 10^{-12}$ & $4.671 \times 10^{-12}$ & 8. $183 \times 10^{-6}$ \\
\hline 40 & $2.836 \times 10^{-12}$ & $4.502 \times 10^{-12}$ & $9.362 \times 10^{-8}$ \\
\hline 41 & $2.421 \times 10^{-12}$ & $4.652 \times 10^{-12}$ & $2.268 \times 10^{-7}$ \\
\hline 42 & 2. $412 \times 10^{-12}$ & 4. $489 \times 10^{-12}$ & $7.794 \times 10^{-8}$ \\
\hline 43 & 2. $292 \times 10^{-12}$ & 4. $439 \times 10^{-12}$ & $8.665 \times 10^{-8}$ \\
\hline 44 & $2.242 \times 10^{-12}$ & $4.537 \times 10^{-12}$ & 1. $220 \times 10^{-7}$ \\
\hline 45 & 2. $054 \times 10^{-12}$ & $4.299 \times 10^{-12}$ & $1.802 \times 10^{-7}$ \\
\hline 46 & $1.601 \times 10^{-12}$ & $4.298 \times 10^{-12}$ & $6.503 \times 10^{-8}$ \\
\hline 47 & 1. $252 \times 10^{-12}$ & 4. $287 \times 10^{-12}$ & 4. $180 \times 10^{-8}$ \\
\hline 48 & $1.252 \times 10^{-12}$ & 4. $345 \times 10^{-12}$ & $6.391 \times 10^{-8}$ \\
\hline 49 & $1.099 \times 10^{-12}$ & $4.354 \times 10^{-12}$ & $1.001 \times 10^{-7}$ \\
\hline 50 & $1.015 \times 10^{-12}$ & $4.364 \times 10^{-12}$ & $5.379 \times 10^{-8}$ \\
\hline
\end{tabular}


Table 3 （B）式によるデー夕使用時の县差の 2 乗和

\begin{tabular}{|c|c|c|c|c|}
\hline DIMEI & ENSION & U BASIC & Sun-FORTRAN & MS-FORTRAN \\
\hline & 1 & $7.961 \times 10^{-6}$ & $7.961 \times 10^{-5}$ & $7.961 \times 10^{-5}$ \\
\hline & 2 & $9.778 \times 10^{-6}$ & $9.778 \times 10^{-8}$ & $9.778 \times 10^{-6}$ \\
\hline & 3 & $2.756 \times 10^{-6}$ & $2.756 \times 10^{-6}$ & $2.756 \times 10^{-6}$ \\
\hline & 4 & $2.754 \times 10^{-6}$ & $2.754 \times 10^{-6}$ & $2.754 \times 10^{-6}$ \\
\hline & 5 & $2.754 \times 10^{-6}$ & $2.754 \times 10^{-6}$ & $2.754 \times 10^{-6}$ \\
\hline & 6 & 2. $728 \times 10^{-6}$ & $2.728 \times 10^{-6}$ & 2. $728 \times 10^{-6}$ \\
\hline & 7 & 2. $726 \times 10^{-6}$ & $2.726 \times 10^{-8}$ & $2.726 \times 10^{-6}$ \\
\hline & 8 & $2.696 \times 10^{-8}$ & $2.696 \times 10^{-6}$ & $2.696 \times 10^{-6}$ \\
\hline & 9 & $2.669 \times 10^{-6}$ & $2.669 \times 10^{-6}$ & $2.669 \times 10^{-6}$ \\
\hline & 0 & $2.653 \times 10^{-6}$ & $2.653 \times 10^{-6}$ & $2.653 \times 10^{-6}$ \\
\hline 1 & 1 & $2.573 \times 10^{-6}$ & $2.573 \times 10^{-6}$ & $2.573 \times 10^{-6}$ \\
\hline 1 & 2 & $2.573 \times 10^{-6}$ & $2.573 \times 10^{-6}$ & 2. $573 \times 10^{-6}$ \\
\hline 1 & $\mathbf{3}$ & 2. $478 \times 10^{-6}$ & 2. $478 \times 10^{-8}$ & $2.890 \times 10^{-6}$ \\
\hline 1 & 4 & 2. $443 \times 10^{-8}$ & 2. $443 \times 10^{-6}$ & $2.501 \times 10^{-6}$ \\
\hline 1 & 5 & 2. $427 \times 10^{-6}$ & $2.427 \times 10^{-8}$ & 2. $455 \times 10^{--}$ \\
\hline 1 & 6 & 2. $343 \times 10^{-6}$ & 2. $343 \times 10^{-6}$ & $2.672 \times 10^{-6}$ \\
\hline 1 & 7 & 2. $289 \times 10^{-6}$ & 2. $289 \times 10^{-6}$ & 2. $485 \times 10^{-6}$ \\
\hline 1 & 8 & 2. $274 \times 10^{-6}$ & $2.274 \times 10^{-8}$ & 2. $480 \times 10^{-6}$ \\
\hline 1 & 9 & $2.092 \times 10^{-6}$ & 2. $092 \times 10^{-6}$ & 2. $486 \times 10^{-6}$ \\
\hline 2 & 0 & $2.028 \times 10^{-8}$ & $2.028 \times 10^{-6}$ & 2. $493 \times 10^{-8}$ \\
\hline 2 & 1 & $2.027 \times 10^{-6}$ & $2.027 \times 10^{-6}$ & $2.522 \times 10^{-6}$ \\
\hline 2 & 2 & $1.932 \times 10^{-6}$ & 1. $932 \times 10^{-6}$ & 2. $439 \times 10^{-8}$ \\
\hline 2 & 3 & $1.668 \times 10^{-6}$ & $1.668 \times 10^{-6}$ & $2.535 \times 10^{-6}$ \\
\hline 2 & 4 & $1.604 \times 10^{-8}$ & $1.606 \times 10^{-6}$ & 2. $302 \times 10^{-6}$ \\
\hline 2 & 5 & $1.603 \times 10^{-6}$ & $1.619 \times 10^{-6}$ & 2. $424 \times 10^{-6}$ \\
\hline 2 & 6 & $1.508 \times 10^{-0}$ & $1.615 \times 10^{-8}$ & 2. $372 \times 10^{-8}$ \\
\hline 2 & 7 & $1.098 \times 10^{-6}$ & $1.608 \times 10^{-6}$ & 2. $290 \times 10^{-6}$ \\
\hline 28 & 8 & $7.943 \times 10^{-7}$ & $2.144 \times 10^{-8}$ & 2. $291 \times 10^{-6}$ \\
\hline 2 & 9 & $3.626 \times 10^{-7}$ & $1.330 \times 10^{-8}$ & 2. $313 \times 10^{-6}$ \\
\hline 3 & 0 & $2.007 \times 10^{-7}$ & 1. $333 \times 10^{-6}$ & 2. $343 \times 10^{-6}$ \\
\hline 3 & 1 & $6.161 \times 10^{-8}$ & $1.338 \times 10^{-6}$ & $2.466 \times 10^{-6}$ \\
\hline 3 & 2 & $2.673 \times 10^{-8}$ & $1.331 \times 10^{-8}$ & 2. $308 \times 10^{-6}$ \\
\hline 3 & 3 & $5.785 \times 10^{-0}$ & $1.251 \times 10^{-6}$ & 2. $262 \times 10^{-8}$ \\
\hline 3 & 4 & $2.059 \times 10^{-0}$ & 2. $473 \times 10^{-8}$ & 2. $533 \times 10^{-8}$ \\
\hline 3 & 5 & $3.596 \times 10^{-10}$ & $1.150 \times 10^{-6}$ & 2. $261 \times 10^{-6}$ \\
\hline 3 & 6 & $1.085 \times 10^{-10}$ & 9. $053 \times 10^{-7}$ & 2. $249 \times 10^{-6}$ \\
\hline 3 & 7 & 2. $025 \times 10^{-11}$ & $8.859 \times 10^{-7}$ & 2. $224 \times 10^{-0}$ \\
\hline 38 & 8 & 8. $017 \times 10^{-12}$ & 2. $942 \times 10^{-7}$ & 2. $240 \times 10^{-6}$ \\
\hline 3 & 9 & $3.277 \times 10^{-12}$ & $2.613 \times 10^{-7}$ & $9.083 \times 10^{-6}$ \\
\hline 4 & 0 & $3.071 \times 10^{-12}$ & $2.856 \times 10^{-7}$ & 2. $185 \times 10^{-6}$ \\
\hline 4 & 1 & $1.815 \times 10^{-12}$ & $2.905 \times 10^{-7}$ & $2.208 \times 10^{-6}$ \\
\hline 4 & 2 & 1. $779 \times 10^{-12}$ & 2. $979 \times 10^{-7}$ & 2. $195 \times 10^{-6}$ \\
\hline 4 & 3 & 1. $725 \times 10^{-12}$ & $7.859 \times 10^{-7}$ & 2. $192 \times 10^{-6}$ \\
\hline 4 & 4 & 1. $704 \times 10^{-12}$ & $9.139 \times 10^{-7}$ & $2.215 \times 10^{-6}$ \\
\hline 45 & 5 & 1. $443 \times 10^{-12}$ & $6.183 \times 10^{-7}$ & 2. $152 \times 10^{-6}$ \\
\hline 46 & 6 & $1.285 \times 10^{-12}$ & $9.862 \times 10^{-7}$ & $2.208 \times 10^{-6}$ \\
\hline 47 & 7 & $1.054 \times 10^{-12}$ & 1. $383 \times 10^{-7}$ & 2. $181 \times 10^{-6}$ \\
\hline 4 & 8 & $1.051 \times 10^{-12}$ & $1.019 \times 10^{-6}$ & 2. $181 \times 10^{-6}$ \\
\hline 48 & 9 & $7.527 \times 10^{-13}$ & $4.766 \times 10^{-7}$ & 2. $171 \times 10^{-6}$ \\
\hline 51 & 0 & 7. $478 \times 10^{-13}$ & $5.467 \times 10^{-7}$ & 2. $187 \times 10^{-6}$ \\
\hline
\end{tabular}




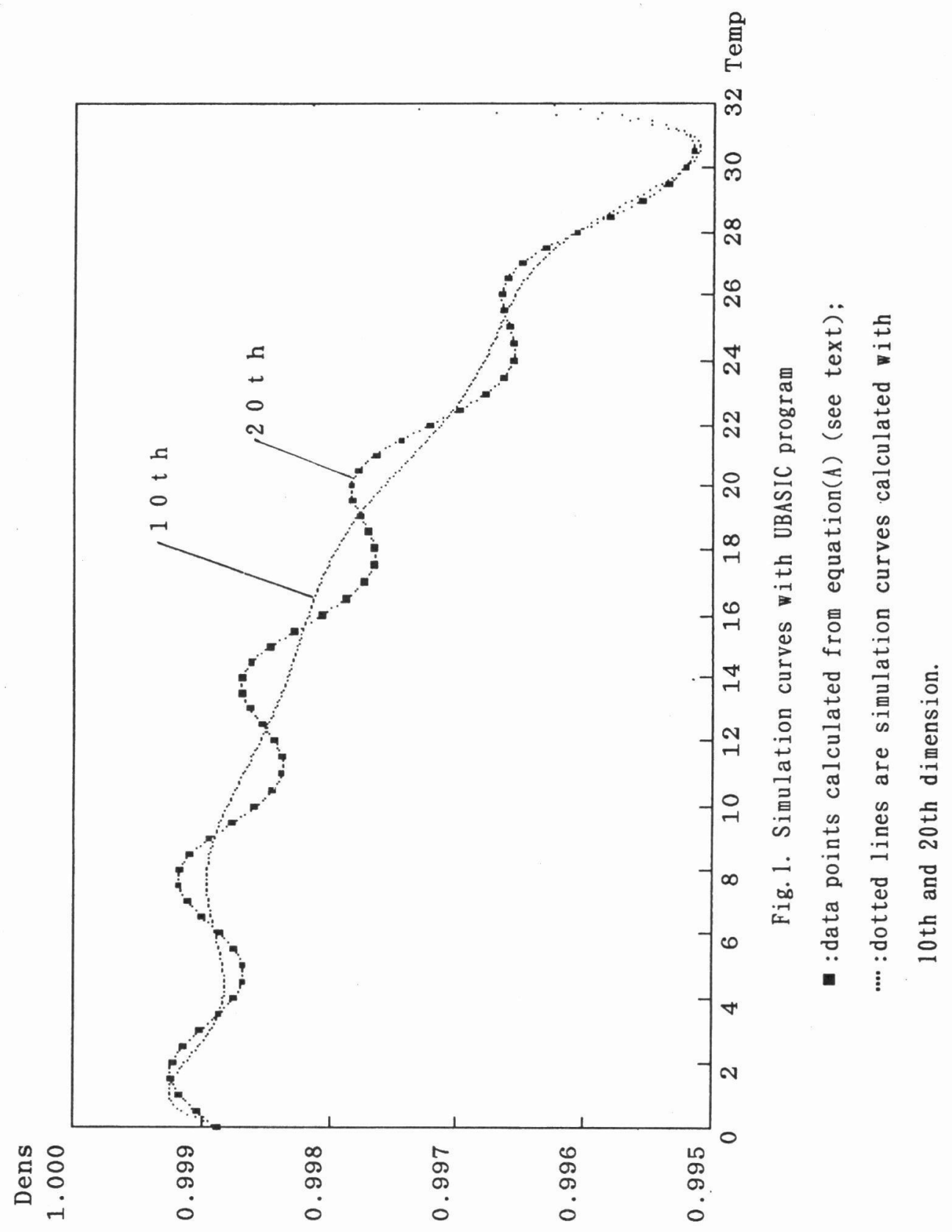



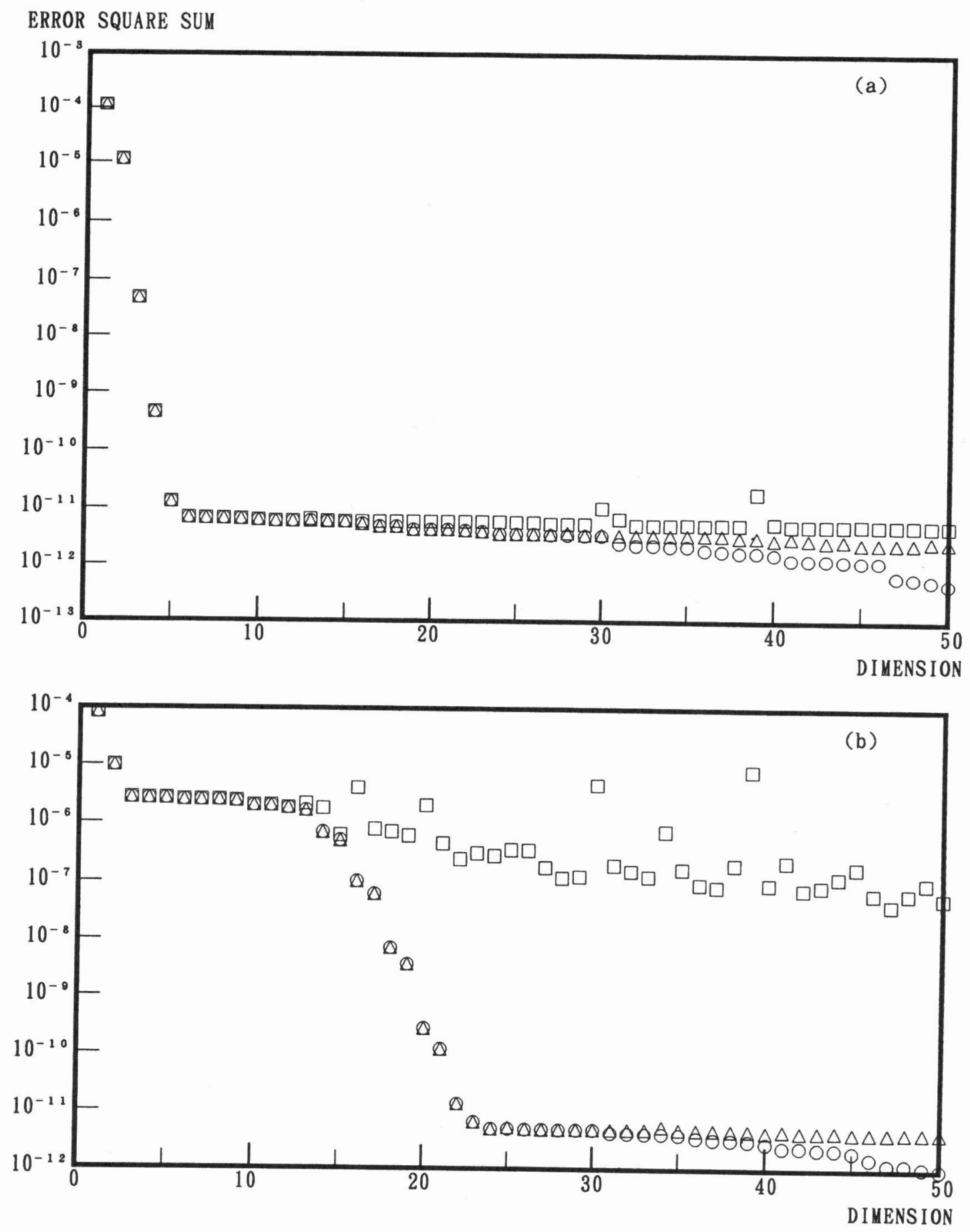

Fig. 2. Relationships between error square sum and dimension for each program

(a): water density data ; (b):equation(A)

$O$ :UBASIC simulation ; $\square$ :MS-FORTRAN simulation

$\triangle$ :Sun-FORTRAN simulation. 


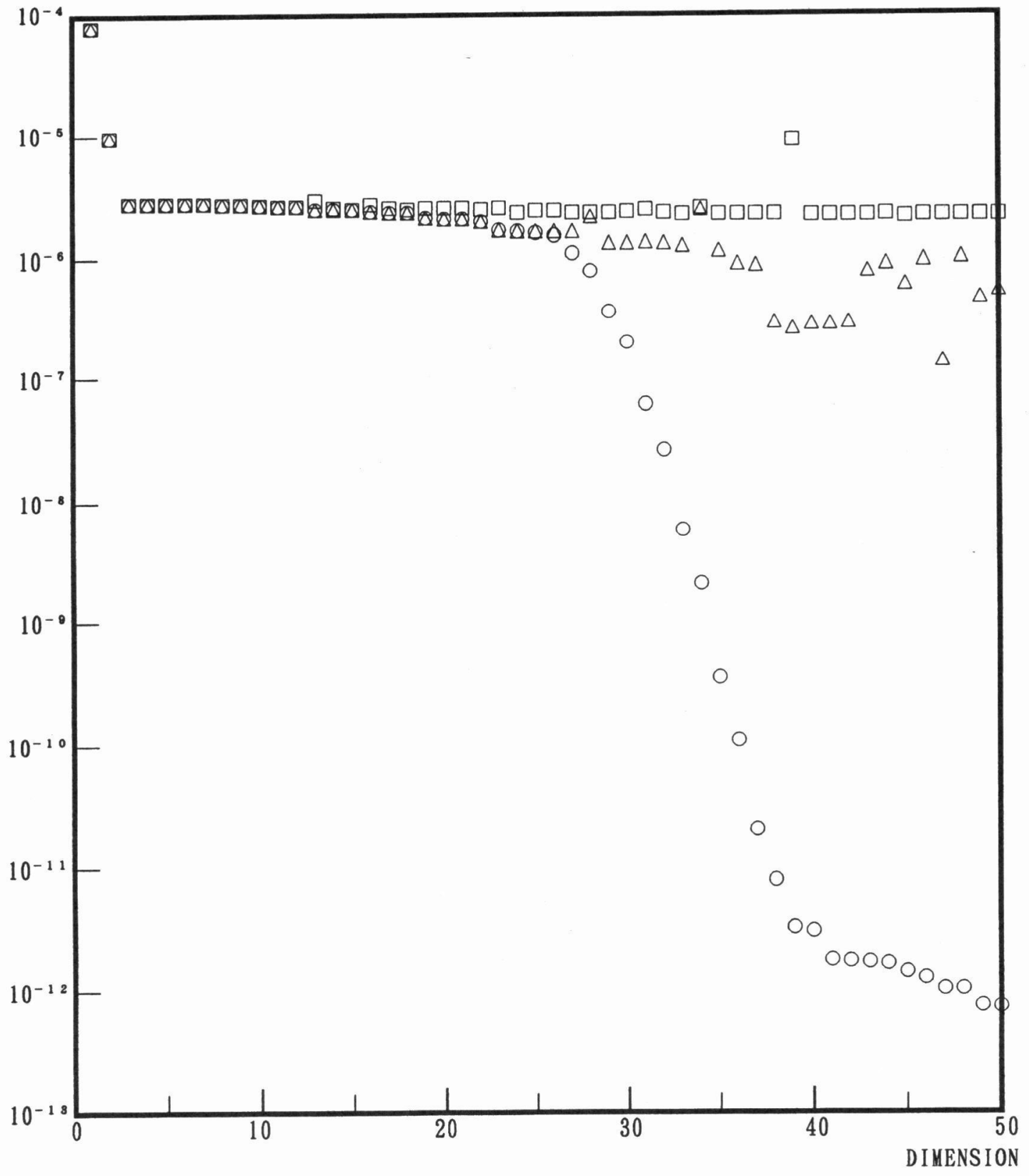

Fig. 3. Relationships between error square sum and dimension for each program equation(B)

O:UBASIC simulation ; $\square$ :MS-FORTRAN simulation $\triangle$ :Sun-FORTRAN simulation. 


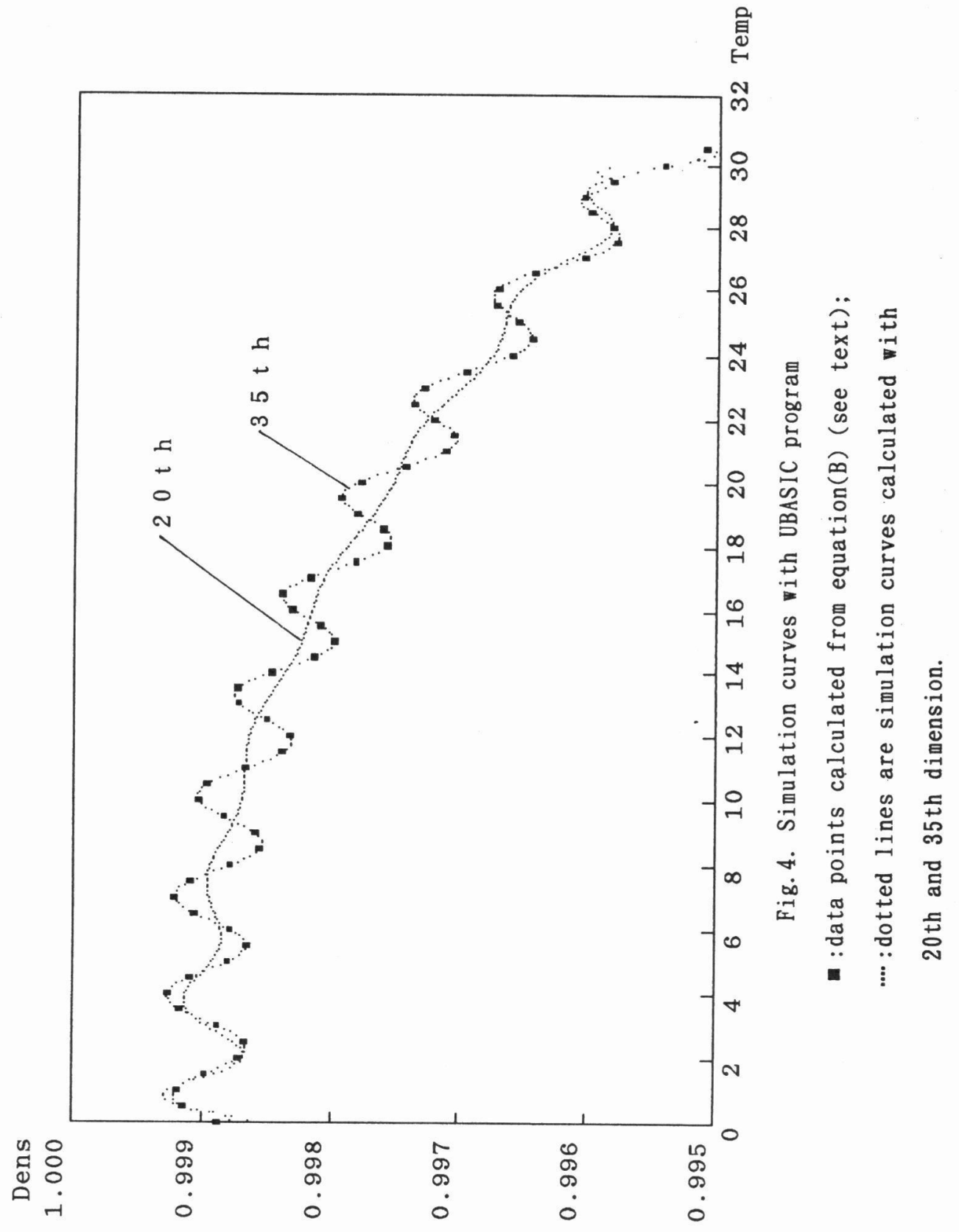




\section{REFERENCES}

1)木田祐司, “U B A S I C 86 Ver8.1 ユーザースマニュアル”、日本評論社 (1990).

2) 成賟芳男・中禁邦夫, 分析化学, 32, T25 (1982).

3）数学ハンドブック編集委員会组, “理エ学のための数学ハンドブック”, p. 326, 丸善 (1960).

4) 一松信・竹之内册編, “改訂增補新数学事典”, 增補 p. 41, 大阪苦籍 (1979).

5）戸川隼人著、“計算機のための数值計算”，p. 18，サイエンス社 (1976).

6）戸川莗人著, ”B A S I Cによる線形代数”，p.46，共立出版（1985）.

7) 矢野健太郎監㤵, 宮本敏雄砡編, “数学ハンドブック”, p. 834, 森北出版（1985）.

(I.N.プロシュテイン・K.A.セメンジャーエフ原著、G.グロッシェ・V.ツィーグラー ・D. ツィーグラー編集)

8) Ref. 5. p. 39.

9) K. Schăfer, G. Beggerow, "Landolt-Börnstein", 6Aufl, II Band, 1T1, s. 36(1971), (Springer Verlag. Berlin•Heidelberg•New York).

Application of U BASIC to chemical calculations

Yoshio NARUSATA* and Yuichi MIYAMAE

Department of Chemistry, College of Science, Rikkyo(St.Paul's) University 3-34-1, Nishi-Ikebukuro, Toshima-ku, Tokyo 171

Te have examined the differences of computational errors and abilities of UBASIC, $\mathrm{N}_{8}$ BASIC and FORTRAN's curve-fitting programs by calculating the least squares method. As a result, the maximum orders of polynomials possible for $N_{3}$ BASIC and US-FORTRAN was 11 th, and for Sun-FORTRAN was 23rd. UBASIC could calculate up to 50 th. Calculation of FORTRAN programs made clear to be meaningless in the higher order of polynomials, because of precisional errors. 